\title{
Multimorbidity among Tuberculosis Cases' Bangladesh Perspective
}

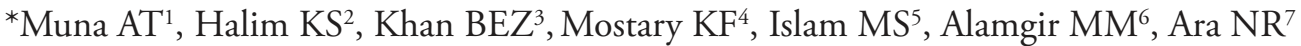

\begin{abstract}
Globally tuberculosis (TB) has become the leading cause of death from infectious diseases. Tuberculosis is a chronic infection and a person may suffer from tuberculosis and other chronic medical conditions at the same time. Co-occurrence of multiple chronic conditions in the same individual, known as multimorbidity (MM) is increasing worldwide. This cross-sectional study was carried out from January 2017 to December 2017 to reveal the extent of multimorbidity among tuberculosis cases. A TB case with multimorbidity was defined as TB with multimorbidity (TB-MM) subject. By convenient sampling, 227 tuberculosis cases from 8 Directly Observed Treatment, Short Course (DOTS) centers from Dhaka, Mymensingh and Netrokona districts were enrolled in this study. Among 227 tuberculosis cases 29 (12.8\%) cases had multimorbidity (TB-MM subjects). Prevalence of multimorbidity was significantly higher in age group $\geq 40$ years $(p<0.001)$, male cases $(p=0.034)$ and cases who had family income $>30000$ BDT/month $(p=0.001)$, were currently smoker $(p=0.028)$ and whose BCG scars were not seen $(p<0.001)$. This study recommends that each TB case should be investigated for other chronic conditions to reveal the actual national magnitude of multimorbidity.
\end{abstract}

Key words: Tuberculois, multimorbidity, co-morbidity.

1. *Dr. Atiya Tasnim Muna, Department of Epidemiology, National Institute of Preventive and Social Medicine (NIPSOM), Mohakhali, Dhaka, E-mail: muna.a.tasnim @gmail.com

2. Dr. Kazi Shafiqul Halim, Associate Professor, Dept. of Epidemiology, National Institute of Preventive and Social Medicine (NIPSOM), Mohakhali, Dhaka.

3. Dr. Bushra-E- Zannat Khan, Department of Epidemiology, National Institute of Preventive and Social Medicine (NIPSOM), Mohakhali, Dhaka.

4. Dr. Kazi Fardana Mostary, Medical Officer, Department of Epidemiology, National Institute of Preventive and Social Medicine (NIPSOM), Mohakhali, Dhaka.

5. Dr. Md. Safikul Islam, Medical Officer, Department of Epidemiology, National Institute of Preventive and Social Medicine (NIPSOM), Mohakhali, Dhaka.

6. Dr. Mohiuddin Mohammad Alamgir, Medical Officer, Upazila Health Complex Nandail, Mymensingh.

7. Dr. Noor Riffat Ara, Deputy Program Manager, CSBA \& Midwifery, Meternal Health, MNCAH, DGHS, Mohakhali, Dhaka.

*For correspondence

\section{INTRODUCTION}

Tuberculosis (TB) has become the ninth leading cause of death worldwide and it has been the leading cause of death from a single infectious agent for last 5 years, which is now ranking above HIV/AIDS. ${ }^{1}$ Despite the availability of affordable, effective treatment; it still affects and kills millions of people each year. In 2016, an estimated 10.4 million people were suffering from tuberculosis globally and 1.7 million died from the disease (including 0.4 million among people with $\mathrm{HIV})^{1}$, which represents an intolerable burden of human suffering. ${ }^{1}$ Ending TB is not only a public health problem, but also a development challenge and opportunity. The WHO "End TB Strategy", aims to end the global TB epidemic with targets to reduce TB deaths by $90 \%$ and TB incidence rate by $80 \%$ by $2030 .{ }^{1}$

In Bangladesh, tuberculosis (TB) is a major public health problem since long ${ }^{2}$ and Bangladesh is one of the 30 high TB burden countries in the world. ${ }^{1,3}$ The goal of National Tuberculosis Control Program is to reduce morbidity, mortality and transmission of TB until it is no longer a public health problem. ${ }^{2}$

Tuberculosis is associated with weakened immune system and it is a chronic infectious disease. Tuberculosis has been reported in association with acute lung infections (viral, bacterial, fungal), HIV infection, chronic helminth infestations, diabetes mellitus, chronic lung disease (e.g., COPD, pneumoconiosis), chronic kidney disease or end stage renal failure, gut malabsorption or gastric bypass surgery, skin disorders (e.g. psoriasis, alopecia areata), sarcoidosis, congenital and other immunodeficiencies, autoimmune diseases, solid organ transplants and cancers. ${ }^{9,10}$

It is not uncommon that a tuberculosis case may also suffer from other long term conditions. ${ }^{9}$ With the increasing pace of globalization, improved life expectancy, ageing populations and the increase in long-term conditions indicate that "multimorbidity" (MM) or the coexistence of two or more chronic conditions in the same individual is rising. ${ }^{7}$

The consequences of multimorbidity include impaired functional status, decreased quality of life, increase in mortality, polypharmacy and complications of treatment, higher utilization of health care system and greater susceptibility to failures of care delivery and coordination and other safety issues. ${ }^{7,22}$ So, finding out the extent of multimorbidty (prevalence and associated factors) among tuberculosis cases is also very important. This study was expected to provide 
information about the extent of multimorbidity among tuberculosis cases in context of Bangladesh.

\section{METHODS}

This cross-sectional study was carried out from January 2017 to December 2017. Eight (8) DOTS centers (National Institute of Diseases of the Chest and Hospital (NIDCH), Dhaka; 250 Bedded TB Hospital, Shyamoli; Dhaka Medical College and Hospital, Upazila Nirbahi parishad, Mymensingh; Mymensingh Medical College and Hospital; Upazila Health Complex Trishal; Upazila Health Complex Nandail and Netrokona District Hospital) under National Tuberculosis Control Program from 3 districts (Dhaka, Mymensingh and Netrokona) under Dhaka and Mymensingh divisions were selected conveniently. By convenient sampling, $227 \mathrm{~TB}$ cases registered in selected DOTS centers were enrolled in this study Available spot cases were interviewed at DOTS centers and a few listed cases (record review) who resided nearby the selected DOTS centers were contacted over phone whether they were available or not and then they were interviewed at their home. A pretested, semi-structured questionnaire was used for data collection. Data were collected by face to face interview, observation and medical records were reviewed for diagnosed chronic diseases. Those TB cases who had chronic conditions but medical records could not be reviewed, were excluded from this study. Informed consent was taken from the respondents and parents/legal guardians (in case of children). A TB case having two or more chronic medical conditions were considered as TB-MM subjects and "TB without MM subjects" if they had no MM.

Prior to commencement of the study, the research protocol was approved by the Ethical Review Board (ERB) of National Institute of Preventive and Social Medicine (NIPSOM). Permission was also taken from the selected DOTS centers. All ethical issues were maintained throughout the study.

Data were processed and analyzed using SPSS version 16.0. Descriptive data were expressed in frequency and percentage. Chi-square test was conducted to find out association of variables with multimorbidity.

\section{RESULTS}

A total of 227 TB cases were interviewed during 1 year study period. Mean age of the tuberculosis cases was $39( \pm 17.01)$ years. About half (40.1\%) of them belonged to 20-39 years age group. Regarding sex distribution, $57.7 \%$ were male and $42.3 \%$ were female. Higher number of cases $(41.4 \%)$ completed their secondary education. More than half of the cases lived in urban area $(57.7 \%)$ and $29.5 \%$ cases were housewives. Mean average monthly income of families of TB cases was 33731.28 ( \pm 23381.09) BDT and half (50.2\%) of them had their average monthly family income 15001-30000 BDT. Majority (81.9\%) of the TB cases was new case and rests (18.1\%) were relapse cases. More than half $(67 \%)$ of the cases suffered from pulmonary tuberculosis and rest suffered from extra-pulmonary tuberculosis (33\%). Regarding smoking habit, 19.4\% TB cases were currently smoker and majority (80.6\%) were found as non-smoker. BCG scar was seen in $55.5 \%$ cases (Table-I).

Table-I: Socio-demographic and health related characteristics of TB cases $(n=227)$

\begin{tabular}{|c|c|c|}
\hline Characteristics & Frequency $(\mathbf{f})$ & Percentage(\%) \\
\hline \multicolumn{3}{|l|}{ Age ( in years) } \\
\hline$<20$ & 27 & 11.9 \\
\hline $20-39$ & 91 & 40.1 \\
\hline $40-59$ & 64 & 28.2 \\
\hline$>59$ & 45 & 19.8 \\
\hline \multicolumn{3}{|c|}{$\begin{array}{ll}\text { Mean } \pm \text { SD } & 39 \pm 17.01\end{array}$} \\
\hline \multicolumn{3}{|c|}{\begin{tabular}{l|l} 
Sex & \\
\end{tabular}} \\
\hline Male & 131 & 57.7 \\
\hline Female & 96 & 42.3 \\
\hline \multicolumn{3}{|l|}{ Educational status } \\
\hline Never attended school & 75 & 33 \\
\hline Up to secondary & 94 & 41.4 \\
\hline Above secondary & 58 & 25.5 \\
\hline \multicolumn{3}{|l|}{ Occupation } \\
\hline Unemployed & 49 & 21.6 \\
\hline Service holder & 42 & 18.5 \\
\hline Business & 34 & 15 \\
\hline Farmer & 25 & 11 \\
\hline Laborer & 10 & 4.4 \\
\hline \begin{tabular}{l|l} 
Housewife &
\end{tabular} & 67 & 29.5 \\
\hline \multicolumn{3}{|c|}{ Family Income (BDT/ month) } \\
\hline Up to 15000 & 34 & 15 \\
\hline $15001-30000$ & 114 & 50.2 \\
\hline$>30000$ & 79 & 34.8 \\
\hline Mean \pm SD $\quad 337$ & $31.28 \pm 23381$. & \\
\hline \multicolumn{3}{|c|}{ Area of residence } \\
\hline Urban & 131 & 57.7 \\
\hline Rural & 96 & 42.3 \\
\hline \multicolumn{3}{|l|}{ Types of Tuberculosis } \\
\hline Pulmonary & 152 & 67 \\
\hline Extra-pulmonary & 75 & 33 \\
\hline \multicolumn{3}{|l|}{ Types of Cases } \\
\hline New & 186 & 81.9 \\
\hline Relapse & 41 & 18.1 \\
\hline \multicolumn{3}{|l|}{ Smoking status } \\
\hline Currently smoker & 44 & 19.4 \\
\hline Non-smoker & 183 & 80.6 \\
\hline \multicolumn{3}{|l|}{ BCG scar } \\
\hline Seen & 126 & 55.5 \\
\hline Not seen & 101 & 44.4 \\
\hline
\end{tabular}


Among 227 TB cases, 29 (12.8\%) cases were found as TB-MM subjects, where 20 had diabetes mellitus, 19 had hypertension, 7 had chronic lung diseases, 6 had arthritis, 6 had chronic kidney disease, 2 had cancer, 2 had Wegener's granulomatosis and 1 had chronic antral gastritis (Table-II).

Among 29 TB-MM subjects, 24 had two and 5 had three chronic diseases.

Table-III shows that age (years, $\mathrm{p}<0.001)$, sex $(\mathrm{p}=0.034)$, smoking status $(\mathrm{p}=.028)$, average monthly family income (BDT/month, $\mathrm{p}=0.001)$ and BCG vaccination status $(<0.001)$ were found to be significantly associated with multimorbidity status in TB cases.
Table-II: Chronic diseases among TB-MM subjects (n=29)

\begin{tabular}{|l|c|c|}
\hline Chronic diseases & Frequency (f) & Percentage (\%) \\
\hline Diabetes mellitus & 20 & 69 \\
\hline Hypertension & 19 & 65.5 \\
\hline Chronic lung diseases & 7 & 24.1 \\
\hline Arthritis & 6 & 20.7 \\
\hline Chronic kidney disease & 6 & 20.7 \\
\hline Cancer & 2 & 6.9 \\
\hline Wegener's granulomatosis & 2 & 6.9 \\
\hline Chronic antral gastritis & 1 & 3.4 \\
\hline
\end{tabular}

Table-III: Association between multimorbidity and health related characteristics of TB cases $(\mathbf{n}=227)$

\begin{tabular}{|c|c|c|c|c|}
\hline \multicolumn{2}{|l|}{ Characteristics } & \multirow{2}{*}{$\begin{array}{c}\text { TB-MM subjects } \\
\begin{array}{c}\text { n=29 } \\
\text { n (\%) }\end{array} \\
2(1.7 \%) \\
27(24.8 \%)\end{array}$} & \multirow{2}{*}{$\begin{array}{c}\text { TB without MM subjects } \\
\begin{array}{c}\mathbf{n}=\mathbf{1 9 8} \\
\mathbf{n}(\%)\end{array} \\
116(98.3) \\
82(75.2)\end{array}$} & \multirow{2}{*}{$\begin{array}{c}\begin{array}{c}\text { p value } \\
\chi^{2}\end{array} \\
<0.001^{*}\end{array}$} \\
\hline Age (years) & $\begin{array}{l}<40 \\
\geq 40\end{array}$ & & & \\
\hline Sex & $\begin{array}{l}\text { Male } \\
\text { Female }\end{array}$ & $\begin{array}{c}22(16.8) \\
7(7.3)\end{array}$ & $\begin{array}{c}109(83.2) \\
89(92.7)\end{array}$ & $0.034^{*}$ \\
\hline Educational status & $\begin{array}{l}\text { Never attended school } \\
\text { Up to secondary } \\
\text { Above secondary }\end{array}$ & $\begin{array}{c}13(17.3) \\
8(8.5) \\
8(13.8)\end{array}$ & $\begin{array}{l}62(82.7) \\
86(91.5) \\
50(86.2)\end{array}$ & 0.225 \\
\hline Occupational status & $\begin{array}{l}\text { Unemployed-housewife } \\
\text { Serviceholder-businessman } \\
\text { Farmer-laborer }\end{array}$ & $\begin{array}{c}11(9.5) \\
13(17.1) \\
5(14.3)\end{array}$ & $\begin{array}{l}105(90.5) \\
63(82.9) \\
30(85.7)\end{array}$ & 0.290 \\
\hline Family income (BDT/month) & $\begin{array}{l}\text { Up to } 15000 \\
15001-30000 \\
>30000\end{array}$ & $\begin{array}{c}6(17.6) \\
5(4.4) \\
18(22.8)\end{array}$ & $\begin{array}{c}28(82.4) \\
109(95.6) \\
61(77.2)\end{array}$ & $0.001^{*}$ \\
\hline Area of residence & $\begin{array}{l}\text { Urban } \\
\text { Rural }\end{array}$ & $\begin{array}{c}20(15.3) \\
9(9.4)\end{array}$ & $\begin{array}{c}111(84.7) \\
87(90.6)\end{array}$ & 0.189 \\
\hline Type of tuberculosis & $\begin{array}{l}\text { Pulmonary } \\
\text { Extra-pulmonary }\end{array}$ & $\begin{array}{l}19(12.5) \\
10(13.3)\end{array}$ & $\begin{array}{c}133(87.5) \\
65(86.7)\end{array}$ & 0.860 \\
\hline Type of cases & $\begin{array}{l}\text { New } \\
\text { Relapse }\end{array}$ & $\begin{array}{c}24(12.9) \\
5(12.2)\end{array}$ & $\begin{array}{c}162(87.1) \\
36(87.8)\end{array}$ & 0.902 \\
\hline Smoking status & $\begin{array}{l}\text { Currently smoker } \\
\text { Non-smoker }\end{array}$ & $\begin{array}{l}10(22.7) \\
19(10.4)\end{array}$ & $\begin{array}{c}34(77.3) \\
164(89.6)\end{array}$ & $0.028^{*}$ \\
\hline BCG scar & $\begin{array}{l}\text { Seen } \\
\text { Not seen }\end{array}$ & $\begin{array}{c}4(3.2) \\
25(24.8)\end{array}$ & $\begin{array}{c}122(96.8) \\
76(75.2)\end{array}$ & $<0.001^{*}$ \\
\hline
\end{tabular}

BCG= Bacillus Calmette-Guérin, BDT= Bangladeshi Taka; p value was extracted using chi square test *indicates statistically significant; 


\section{DISCUSSION}

Over recent years, people living with multiple chronic conditions known as "multimorbidity" is rising in prevalence $^{7,11}$, both in developed ${ }^{12}$ and developing countries. ${ }^{13}$ On the other hand, tuberculosis, a chronic infectious disease, is a major public health problem in Bangladesh for a long period of time. Tuberculosis can frequently co-occur with other long-term medical conditions. ${ }^{8,9,10}$ Therefore, present study was designed to find out the extent of multimorbidity among tuberculosis cases in our country and it should be stated that, a study was conducted on general rural elderly people to investigate multimorbidity in our country ${ }^{24}$; another study was found regarding tuberculosis-diabetes comorbidity ${ }^{14}$ but studies regarding multimorbidity in similar tuberculosis population were very rarely found in Bangladesh. However, in Brazil, a study was conducted on all the reported TB cases registered in their National Notification System showed increased number of tuberculosis subjects presenting with multimorbidity (MM). MM increases the iniquity contributing to adverse clinical outcomes and treatment response in patients with $\mathrm{TB}^{4}{ }^{4}$

In this study, Mean age (including standard deviation) of the tuberculosis cases was $39( \pm 17.01)$ years and most of the cases belonged to the 20-39 years age group (40.1\%). More than half of the tuberculosis cases in this study were male $(57.7 \%)$ and the rest were female (42.3\%). Almost half $(41.4 \%)$ of the tuberculosis cases completed secondary education. and half of the cases $(50.2 \%)$ belonged to 15001-30000 taka income group. People from urban area $(57.7 \%)$ suffered more from tuberculosis than rural area (42.3\%). Regarding clinical characteristics of TB cases, more than half of the cases suffered from pulmonary tuberculosis (67\%) and rest suffered from extra-pulmonary tuberculosis (33\%). Majority of the cases $(81.9 \%)$ were new cases and rest were relapse cases (18.1\%). Tobacco smoking is associated with poor TB treatment results. ${ }^{15,16}$ In this study, $19.4 \%$ cases were found as currently smoker. BCG scar was seen in $55.5 \%$ of all TB cases. Malabika Sarker et al. conducted a study in order to measure the burden of TB-diabetes co-morbidity in Bangladesh, where the mean age (including standard deviation) of the tuberculosis cases was $39.9( \pm 15.5)$ years, $38.7 \%$ were females, about half $(53.1 \%)$ of them had a family income of 5000-10,000 BDT, 40.7\% never attended school and more than half $(59.2 \%)$ of the cases were from rural areas. About $82.2 \%$ had pulmonary TB where most of the cases (98.2\%) were new cases. ${ }^{14}$
The proportion of multimorbidity among tuberculosis cases (TB-MM subjects) in this study was $12.8 \%$ where 24 (82.76\%) TB-MM subjects had 2 and 5 (17.24\%) had 3 chronic diseases along with tuberculosis. The finding is higher than the prevalence of multimorbidity in tuberculosis cases $(1.14 \%)$ in Brazil. ${ }^{4}$ However, this difference might be due difference in sample size where that study was conducted on all the tuberculosis cases registered in the National Notification system in Brazil.

Multimorbdity and age has very strong and well-recognized association. ${ }^{4,20}$ The prevalence of multimorbidity increases substantially with age. ${ }^{7}$ In this study, proportion of multimorbidity among tuberculosis cases was significantly higher in age group $\geq 40$ years $(\mathrm{p}<0.001)$. This finding agrees with Reis-Santos et al study where 40-59 years (OR: 17.89; 95\% CI, 5.71-56.03) and those $\geq 60$ years (OR: 44.11; 95\% CI, 14.09-138.06) were more likely to develop TB-MM. ${ }^{4}$

Gender is also one of the determinants of both $\mathrm{TB}^{23}$ and MM. ${ }^{7,21}$ Generally, TB is more frequent in $\operatorname{men}^{23}$ but women more often develop multimorbidity. ${ }^{21}$ In this study, sex of the tuberculosis cases was found to be significantly associated with multimorbidity $(\mathrm{p}=0.034)$. In Brazil, simultaneous occurrence of TB and MM was lower for males (OR: 0.63; 95\% CI, 0.52-0.76). ${ }^{4}$

Level of education can affect the probability of having tuberculosis and multimorbidity. ${ }^{4}$ Our study shows that higher proportion of multimorbidity was found in tuberculosis cases who never attended school ( $p>0.05$ ). The study conducted in Brazil revealed that higher proportion (1.7\%) of TB-MM subjects were illiterate . ${ }^{4}$

In our study we found that urban tuberculosis cases had higher proportion of multimorbidity than rural cases $(\mathrm{p}>$ 0.05). Another previous study that showed TB-MM subjects were less likely to live in rural areas (OR: 0.63; 95\% CI, 0.42-0.95). ${ }^{4}$ In this study, monthly family income was found significantly $(\mathrm{p}=0.001)$ associated with multimorbidity in tuberculosis cases. It is known to us that poverty is one of the determinants of tuberculosis. A study conducted on multimorbidity in rural elderly people in our country showed that persons who were relatively better-off, suffered from more chronic conditions. ${ }^{24}$

Type of tuberculosis and type of tuberculosis cases are important factors in disease diagnosis and treatment but no significant association was found between these factors and multimorbidity, which reflects the findings of the Brazilian study. ${ }^{4}$ 
Prevalence of multimorbidity was significantly $(\mathrm{p}=0.028)$ higher among currently smoker tuberculosis cases. Smoking prevalence is often high among TB cases. As a result, prevalence of other smoking-related conditions can be high as well in people with TB. ${ }^{15,16} \mathrm{~A}$ study conducted on multimorbidity in general population in China showed that smoker people were more likely to develop multimorbidity. ${ }^{13}$

In this study it was observed that proportion of multimorbidity was significantly $(\mathrm{p}<0.001)$ higher in tuberculosis cases without having BCG scar. However studies regarding $\mathrm{TB}$ vaccine efficacy and multimorbidity were very rarely found.

\section{CONCLUSIONS}

The current study showed increased number of TB-MM subjects in our country and multimorbidity among tuberculosis cases was significantly associated with age, sex, monthly family income, smoking habit and BCG vaccine scar. However, the study was conducted on a small scale. Moreover, tuberculosis cases who had other morbidities but medical records could not be reviewed, were excluded from this study. So, prevalence of multmorbidity in TB cases might have been underestimated. Subjects with MM may be prone to TB-drug intolerance, treatment failure and need a longer duration of treatment. ${ }^{4}$ Therefore; it is proposed that a systemic nationwide study should be conducted on each tuberculosis case to get the actual national scenario of multimorbidity.

\section{REFERENCES}

1. World Health Organization. Global tuberculosis report 2017 [Internet]. Geneva: World Health Organization; 2017 [cited 2017 Nov 8]. 262 p.

2. NTP. National Tuberculosis Control in Bangladesh. Annual Report 2016. National Tuberculosis Control Program, DGHS, Dhaka.

3. World Health Organization. "Global tuberculosis report 2016."

4. Reis-Santos B, Gomes T, Macedo LR, Horta BL, Riley LW, Maciel EL. Prevalence and patterns of multimorbidity among tuberculosis patients in Brazil: a cross-sectional study. International journal for equity in health. 2013 Dec;12(1):61.

5. Ording AG, Sørensen HT. Concepts of comorbidities, multiple morbidities, complications, and their clinical epidemiologic analogs. Clinical epidemiology. 2013;5:199.

6. Barnett K, Mercer SW, Norbury M, Watt G, Wyke S, Guthrie B. Epidemiology of multimorbidity and implications for health care, research, and medical education: a cross-sectional study. The Lancet. 2012 Jul 7;380(9836):37-43.

7. Mercer S, Furler J, Moffat K, Fischbacher-Smith D, Sanci L. Multimorbidity: Technical Series on Safer Primary Care.

8. Mori T, Leung CC. Tuberculosis in the global aging population. Infectious Disease Clinics. 2010 Sep 1;24(3):751-68.

9. Bates M, Marais BJ, Zumla A. Tuberculosis comorbidity with communicable and noncommunicable diseases. Cold Spring Harbor perspectives in medicine. 2015 Nov 1;5(11): a017889.

10. Marais BJ, Lönnroth K, Lawn SD, Migliori GB, Mwaba P, Bates M, et al. Tuberculosis comorbidity with communicable and non-communicable diseases: integrating health services and control efforts. The Lancet infectious diseases. 2013 May 1;13(5):436-48.

11. Uijen AA, van de Lisdonk EH. Multimorbidity in primary care: prevalence and trend over the last 20 years. The European journal of general practice. 2008 Jan 1;14(sup1):28-32.

12. Barnett K, Mercer SW, Norbury M, Watt G, Wyke $S$, Guthrie B. Epidemiology of multimorbidity and implications for health care, research, and medical education: a cross-sectional study. The Lancet. 2012 Jul 7;380(9836):37-43.

13. Wang HH, Wang JJ, Wong SY, Wong MC, Li FJ, Wang PX, et al. Epidemiology of multimorbidity in China and implications for the health care system: cross- sectional survey among 162,464 community household residents in southern China. BMC Med. 2014;12(1):188.

14. Sarker M, Barua M, Guerra F, Saha A, Aftab A, Latif $\mathrm{AM}$, et al. Double trouble: prevalence and factors associated with tuberculosis and diabetes comorbidity in Bangladesh. PloS one. 2016 Oct 31;11(10): e0165396.

15. World Health Organization. A WHO/The Union monograph on $\mathrm{TB}$ and tobacco control: joining efforts to control two related global epidemics. InA 
WHO/the Union monograph on TB and tobacco control: joining efforts to control two related global epidemics 2007.

16. Murray JF, Pio A, Ottmani S. PAL: a new and practical approach to lung health. The International Journal of Tuberculosis and Lung Disease. $2006 \mathrm{Nov}$ 1;10(11):1188-91.

17. Davenne T, McShane H. Why don't we have an effective tuberculosis vaccine yet?. Expert review of vaccines. 2016 Aug 2;15(8):1009-13.

18. Rafi W, Ribeiro-Rodrigues R, Ellner JJ, Salgame P. Coinfection-helminthes and tuberculosis. Current opinion in HIV and AIDS. 2012 May 1;7(3):239-44.

19. Zevallos K, Vergara KC, Vergara A, Vidal C, Garcia $\mathrm{HH}$, Evans CA. Tuberculin skin-test reactions are unaffected by the severity of hyperendemic intestinal helminth infections and co-infections. The American journal of tropical medicine and hygiene. 2010 Aug 5;83(2):319-25.
20. Fortin M, Stewart M, Poitras ME, Almirall J, Maddocks H. A systematic review of prevalence studies on multimorbidity: toward a more uniform methodology. The Annals of Family Medicine. 2012 Mar 1;10(2):142-51.

21. Fortin M, Hudon C, Haggerty J, van den Akker M, Almirall J. Prevalence estimates of multimorbidity: a comparative study of two sources. BMC health services research. 2010 Dec;10(1):111.

22. Gijsen R, Hoeymans N, Schellevis FG, Ruwaard D, Satariano WA, van den Bos GA. Causes and consequences of comorbidity: a review. Journal of clinical epidemiology. $2001 \mathrm{Jul}$ 1;54(7):661-74.

23. Lawn SD, Zumla AI. Tuberculosis. Lancet. 2011;378(9785):57-72.

24. Khanam MA, Streatfield PK, Kabir ZN, Qiu C, Cornelius C, Wahlin A. Prevalence and patterns of multimorbidity among elderly people in rural Bangladesh: a cross-sectional study. Journal of health, population, and nutrition. 2011 Aug;29(4):406. 